Published in final edited form as:

Scand J Pain. 2016 October ; 13: 12-16. doi:10.1016/j.sjpain.2016.05.037.

\title{
Total Sleep Deprivation and Pain Perception during Cold Noxious Stimuli in Humans
}

\author{
Robert A. Larson, MS and Jason R. Carter, PhD \\ Department of Kinesiology and Integrative Physiology, Michigan Technological University, \\ Houghton, MI
}

\section{Abstract}

Background and Aims-A substantial portion of the population suffers from chronic pain leading to significant health care costs and lost productivity. Loss of sleep duration and quality are widely reported in patients suffering from a variety of acute or chronic pain conditions. Conversely, sleep loss has been known to elevate pain perception; thus a potential bi-directional relationship exists between sleep deprivation and pain. To date, the majority of studies examining the relationship between experimentally induced pain and sleep loss have focused on the measurement of pain threshold. Additionally, despite evidence of sex differences in ratings of perceived pain, previous studies examining pain following sleep loss have not probed for sex differences. We examined the effects of 24-hour total sleep deprivation (TSD) on perceived pain during a 2-minute cold pressor test (CPT). We hypothesized that TSD would augment perceived pain and that women would demonstrate an elevated pain response compared to men.

Methods-Testing was carried out in 14 men and 13 women. All subjects reported to be nonsmokers with no history of cardiovascular disease, autonomic dysfunction, asthma, or diabetes. All female subjects were free of oral contraceptive use, and were tested during the early follicular phase of the menstrual cycle. Trial order was randomized and testing sessions (Normal sleep (NS) and TSD) were separated by approximately one month. Subjects immersed their left hand, up to the wrist, in an ice water bath $\left(\sim 1^{\circ} \mathrm{C}\right)$, and perceived pain was recorded every 15 seconds from a modified Borg scale (6-20 arbitrary units a.u.).

Results-Perceived pain responses during CPT were augmented following TSD ( $\Delta 1.2$ a.u.; time $x$ condition, $\mathrm{p}<0.05$ ). The augmented pain response following TSD was noted when perceived pain was expressed as mean (NS $\Delta 7.0 \pm 0.5$ vs. TSD $\Delta 8.2 \pm 0.5$ a.u.; $\mathrm{p}<0.05$ ) or peak (NS $\Delta 8.9 \pm 0.6$ vs. TSD $\Delta 10.2 \pm 0.5$ a.u.; $\mathrm{p}<0.05$ ) perceived pain. The effects of TSD on perceived pain were similar in both men and women (condition $\times$ time $\times$ sex, $p>0.05$ ).

Address for Correspondence: Jason R. Carter, Ph.D., Department of Kinesiology and Integrative Physiology, Michigan Technological University, 1400 Townsend Drive, Houghton, MI 49931, Phone: (906) 487-2715, Fax: (906) 487-0985, jcarter@mtu.edu.

Publisher's Disclaimer: This is a PDF file of an unedited manuscript that has been accepted for publication. As a service to our customers we are providing this early version of the manuscript. The manuscript will undergo copyediting, typesetting, and review of the resulting proof before it is published in its final citable form. Please note that during the production process errors may be discovered which could affect the content, and all legal disclaimers that apply to the journal pertain.

DISCLOSURES

The authors do not have any conflicts of interest to disclose. 
Conclusions and Implications-We conclude that TSD significantly augments perceived pain during CPT, but this response was not sex dependent. These findings support emerging evidence that adequate sleep represents a relevant, and cost effective, preventative/therapeutic strategy to reduce self-perceived pain in both men and women.

\section{Keywords}

Cold pressor test; nociceptors; sex differences; insomnia; sleep restriction

\section{INTRODUCTION}

Approximately 19\% of adult Americans suffer from some form of persistant pain[1]. The economic cost of chronic pain in terms of health care and lost productivity in the United States is estimated somewhere between $\$ 560$ and $\$ 635$ billion per year [2]. Understanding the processes involved in pain sensation, and developing cost-effective strategies for the management of pain are of clinical and economic importance.

Most humans spend nearly one-third of their lives sleeping, and proper sleep hygiene is critical to overall health and wellness. Unfortunately, there has been a steady decline in both sleep duration and quality in humans of all ages over the past 30 years. Epidemiological studies report an association between chronic pain and sleep loss [3-8], and it is widely accepted that the relationship between pain and sleep loss is bidirectional. As such, treatment strategies remain complex and dependent upon which condition (pain vs. sleep deprivation) is believed to be the primary modulator. Nevertheless, sleep represents a costeffective, nonpharmaceutical strategy for pain management.

Cooperman et al. [9] was the first to report a decrease in cutaneous pain threshold as measured with von Frey hairs in six male subjects during a 60 hour sleep deprivation protocol. In more recent years, the observations made by Cooperman et al. [9] have been supported using a variety sleep loss paradigms and methods of stimuli in humans [10-13]. However, these studies have primarily focused on assessment of pain threshold. In contrast to pain threshold analyses, sustained cold noxious stimuli have been shown to produce greater pain ratings that more closely mimic clinical pain conditions than pain threshold analysis [14]. To our knowledge, no studies have examined the influence of experimentallyinduced 24-hour total sleep deprivation (TSD) on sustained pain elicited by a classic cold pressor test.

Finally, while several studies have examined the influence of sleep deprivation on pain threshold [9-11, 15], these studies have not probed into potential sex differences. This is surprising because there is considerable evidence indicating sex differences in pain ratings with women generally reporting elevated sensitivity to experimentally induced pain than men [16-18]. Furthermore, studies suggest that reports of clinical or chronic pain are more prevalent in women compared to men [19, 20]. Despite evidence of sex differences in both experimental and clinical pain, the relations between sleep deprivation, pain, and sex remain equivocal. 
The purpose of the present study was to 1) examine the influence of sleep deprivation on pain perception to cold noxious stimuli in humans, and 2) determine if the effects of TSD on perceived pain produce a differential response between men and women. We hypothesized that TSD would augment pain perception elicited via the classic cold pressor test, and that this augmentation would be more dramatic in women compared to men.

\section{MATERIAL AND METHODS}

\subsection{Subjects}

Thirty healthy subjects ( 15 men and 15 women) enrolled in the study. Autonomic and cardiovascular responses at rest [21] and during acute stress [22] have been previously reported. All subjects reported to be nonsmokers with no history of cardiovascular disease, autonomic dysfunction, asthma, or diabetes. All female subjects were free of oral contraceptive use, reported regular menstrual cycles (range 26-30 days), and were tested during the early follicular phase (2-5 days after the onset of menstruation) of the menstrual cycle. One female subject was excluded from the study when estradiol and progesterone levels indicated she was not in the early follicular phase for one testing session. All subjects were screened for obstructive sleep apnea by a board certified sleep physician using the at home ApneaLink (Resmed, San Diego, CA). Exclusion from the study occurred when the apnea-hypopnea index was $\geq 10$ arbitrary units, and one male subject was excluded on this basis. Additionally, one female subject was excluded due to failure to complete the CPT session resulting in a total sample size of 27 (14 men: $22 \pm 1$ years, $176 \pm 2 \mathrm{~cm}, 79 \pm 4 \mathrm{~kg}$; 13 women: $22 \pm 1$ years, $165 \pm 2 \mathrm{~cm}, 63 \pm 3 \mathrm{~kg}$ ). All subjects participated in an orientation session before providing written informed consent. This study was approved by the Michigan Technological University Institutional Review Board.

\subsection{Experimental Design}

Two experimental testing sessions were performed: one following a normal night of sleep (NS), and one following 24-hour TSD. Subjects were tested approximately one month apart to ensure females were tested during the early follicular $(\mathrm{EF})$ phase of the menstrual cycle. Trial order (NS vs. TSD) was randomized using a crossover design. Specifically, 7 women and 5 men were assigned to the NS trial first, while the remaining subjects ( 7 women and 9 men) were assigned the TSD trial first. Sleep time for 3 days preceding the study was monitored with wrist actigraphy (Actiwatch 64 Respironics Inc, Bend OR) to ensure subjects were getting adequate sleep.

The day prior to the TSD trial, subjects were contacted at 7:30 a.m. and instructed to refrain from napping during the day. They reported to the laboratory at 11:00 p.m. where two assistants ensured they did not sleep or close their eyes during the night. Subjects participated in light activities including reading, studying, and games with the assistants during the TSD protocol. Subjects refrained from caffeine, alcohol and exercise for 12 hours, and fasted for 8 hours prior to testing. 


\subsection{Protocol}

On each day of testing (i.e., NS and TSD), 3 consecutive recordings of resting blood pressure ( $\sim 1$ minute apart) were taken with an automated sphygmomanometer (Omron HEM-907XL, Omron Health Care) following 5 minutes of seated rest. Following a standard breakfast, subjects assumed a supine position on the testing table for instrumentation. Beatto-beat blood pressure, heart rate, and muscle sympathetic nerve activity (MSNA) were continuously recorded during a 10 min baseline, 5 min mental stress trial, and 2 min cold pressor trial; the autonomic and cardiovascular responses in these various sessions have been previously reported $[21,22]$. The present study specifically focuses on the self-reported pain ratings obtained during the cold pressor test. Briefly, the cold pressor test (CPT) trial consisted of a 3-minute resting supine baseline, 2 minute CPT, and 3 minute recovery. During CPT, subject's immersed their left hand up to the wrist in a mixture of ice and water $\left(\sim 1^{\circ} \mathrm{C}\right)$. Ratings of perceived pain were recorded every 15 seconds when one research assistant would instruct the subject to verbally identify a pain rating from a modified Borg scale for pain (6-20 arbitrary units) situated in the subject's field of view. As depicted in Table 1, a rating of 6 corresponds to no pain whereas a rating of 20 indicates unbearable pain.

\subsection{Statistical Analysis}

All statistical analyses were performed using commercial software (SPSS 20.0, SPSS, Chicago, IL). We used repeated-measures ANOVA with condition (NS vs. TSD) and time (i.e., $15 \mathrm{sec}$ epochs during CPT) as the within-subjects factors, and sex (men vs. women) as a between-subjects factor. Post-hoc analyses (least significance difference) were performed when significant condition by sex interactions (i.e., baseline data) or significant condition $x$ time $\times$ sex interactions (i.e., CPT trial) were detected. Results are expressed as mean $\pm \mathrm{SE}$; significant differences were noted at $\mathrm{p}<0.05$.

\section{RESULTS}

\subsection{Baseline}

Baseline hemodynamic data has been reported and discussed [21]. Sleep time for the three nights preceding the study was not different between NS $(7.3 \pm 0.2 \mathrm{~h}$ in men and $7.6 \pm 0.2 \mathrm{~h}$ in women) and TSD ( $7.6 \pm 0.3 \mathrm{~h}$ in men and $7.5 \pm 0.3 \mathrm{~h}$ in women) conditions.

\subsection{Perceived Pain Responses to CPT}

Figure 1 illustrates that perceived pain increased during CPT following both NS and TSD conditions (time, $\mathrm{p}<0.05$ ), and that perceived pain was augmented following TSD when compared to NS (time $\times$ condition, $\mathrm{p}<0.05$ ). The augmented pain response to CPT following TSD was also present when perceived pain was expressed as mean (NS $\Delta 6.9 \pm 0.5$ vs. TSD $\Delta 8.2 \pm 0.5$ arbitrary units, condition, $\mathrm{p}<0.01$ ) or peak perceived pain (NS $\Delta 8.9 \pm 0.6$ vs. TSD $\Delta 10.2 \pm 0.5$ arbitrary units, condition, $\mathrm{p}<0.01$ ) as displayed in Figure 2 . Figure 3 demonstrates that TSD resulted in an enhance pain response in men and women, however there were no statistical sex differences in perceived pain during CPT after either sleep condition (Table 2; condition $\times$ time $\times$ sex, $\mathrm{p}>0.05$ ). 


\section{DISCUSSION}

The current study examined the influence of 24-hour TSD on perceived pain during CPT, and we report two novel findings. First, TSD augmented perceived pain during CPT, a finding that was consistent with our primary hypothesis. Second, contrary to our secondary hypothesis, there were no sex differences in perceived pain response to CPT following TSD. To date, studies examining the interaction between TSD and pain perception have focused on experimentally-induced pain threshold or self-reported pain symptoms. The use of a sustained CPT to elicit pain has been suggested to provide a closer approximation to clinical pain than other measures such as threshold analysis [14], thus the methodology of the present study provides important and new insights in the field of sleep deprivation and pain.

Previous studies suggest that sleep deprivation, or sleep loss, results in an augmented pain response in healthy subjects [9-12, 23, 24]. Hyperalgesia has also been demonstrated following sleep loss in patients suffering from fibromyalgia [24, 25]. The testing paradigms demonstrating hyperalgesia following sleep loss indicate an increased sensitivity to mechanical and heat stimuli, however, only one study included noxious cold stimuli following sleep loss and reported a trend towards an augmented pain response when examining pain threshold [11]. The current study demonstrates that 24-hour TSD augments the perceived pain response to a sustained CPT.

Evidence suggests that pain and sleep share a bidirectional relationship, and that sleep disturbances and sleep loss are common in patients with many forms of chronic pain [26, 27], back pain [28-30], and rheumatoid arthritis [31, 32]. Studies have demonstrated that experimentally induced pain during sleep in healthy subjects results in micro-arousals [33, 34] and elevations in heart rate [35]. These studies demonstrate that pain can have a significant impact on sleep structure, and that arousals due to pain may contribute to the reports of disrupted or non-restorative sleep in patients with chronic pain. Conversely, one recent study has demonstrated that extending subjects' bedtime, and therefore sleep time, resulted in a reduction in pain sensitivity [36]. Given the findings of augmented pain perception during CPT in the present study, future work might focus on these patient populations with higher incidence of pain.

Kunderman et al. [11] examined thermal sensitivity to determine if a change in overall somatosensory sensitivity was responsible for hyperalgesia following TSD. Their results indicate that thermal sensitivity was not altered by TSD, and therefore the changes in pain threshold were due to mechanisms other than a change in general somatosensory sensitivity. The question then arises as to what is responsible for the change in pain perception after sleep loss. Studies in animals suggest a possible impairment in the endogenous opioid system contributing to an augmented pain response [37, 38]. Furthermore, Smith et al. [13] employed a diffuse noxious inhibitory control (DNIC) protocol following partial sleep deprivation and demonstrated a reduction in pain inhibitory capacity. These results suggest an alteration in pain inhibition following sleep deprivation that is often attributed to endogenous opioids. The mechanism responsible for the augmented pain response following sleep loss requires more attention with a greater emphasis on data from human subjects. 
In the present study, we examined both men and women to determine if TSD produced a differential perceived pain response to CPT. Women tend to report a higher prevalence of chronic pain compared to men [20], and evidence suggests that the pain response to experimentally-induced noxious stimuli can vary between the sexes, with women generally report more pain than men [17-20]. Contrary to our hypothesis, the current study demonstrated no sex differences in pain intensity during CPT. Sex differences in experimentally induced pain appear to be somewhat dependent on the experimental paradigm and stimulus modality, and could be further influenced by menstrual phase in female subjects $[19,40]$. In the current study, all female subjects were free of oral contraceptive use, and tested during the EF phase of the menstrual cycle to minimize variability due to hormone levels. In addition we utilized CPT to provide a widespread and sustained stimulus, thereby resulting in activation of a large subset of nociceptors. While many studies report sex differences to noxious cold stimuli [17, 41-45], the data are variable and studies also report no sex differences [46-49]. However, sex differences are most consistent for cold stimuli when examined with measures beyond threshold such as tolerance and perceived pain ratings [19]. We did not observe sex differences in perceived pain responses to CPT during either trial. The lack of sex differences could be attributed, in part, to the fact that we tested females only during the EF phase of the menstrual cycle considering that evidence suggests pain sensitivity may be elevated during the high hormone phases of the menstrual cycle in females [50,51]. Sleep loss was the primary variable of interest in the present study, and therefore, ensuring subject hormone levels were similar, was critical for the experimental design. The current study suggests that the factors mediating a differential pain response between the sexes are not significantly influence by TSD.

We acknowledge a number of study limitations. First, we did not utilize electroencephalogram (EEG) during the 24-hour sleep deprivation, thus we cannot be certain the subjects did not have some brief "microsleep" during this time. However, our subjects were continuously monitored and engaged in activities throughout the TSD night, thus we are confident there was extremely limited to no "microsleep" episodes in our subjects. Second, we acknowledge that our modified Borg scale for perceived pain is unique, and that future studies might utilize a standard 0-10 scale. Importantly, we do not believe the range of our subjective pain scale negatively influences the primary findings.

\section{CONCLUSIONS}

In summary, 24-hour TSD increased pain intensity responses during CPT. The augmented pain response to sustained noxious cold stimuli following TSD extends the findings provided by pain threshold analysis in that extended exposure to painful stimuli provides a closer association to clinical pain [14]. Sleep deprivation and sleep loss can augment perceived pain and adequate sleep represents a relevant and nonpharmacological method to diminish self-reported perceived pain. 


\section{ACKNOWLEDGMENTS}

The authors wish to acknowledge Dr. Joseph DellaValla, the board certified sleep physician who assisted with the analysis of the Actiwatch and ApneaLink screening data. We also thank Huan Yang and John Durocher for their assistance with this project.

Source of Funding:

This project was supported by the National Institutes of Health (HL-098676).

\section{References}

1. Kennedy J, Roll JM, Schraudner T, Murphy S, McPherson S. Prevalence of persistent pain in the U.S. adult population: new data from the 2010 national health interview survey. J Pain. 2014; 15:979-84. [PubMed: 25267013]

2. Gaskin DJ, Richard P. The Economic Costs of Pain in the United States. J Pain. 2012

3. Atkinson J, Ancoli-Israel S, Slater MA, Garfin SR, Gillin C. Subjective sleep disturbance in chronic back pain. Clin J Pain. 1988; 4:225.

4. Pilowsky I, Crettenden I, Townley M. Sleep disturbance in pain clinic patients. Pain. 1985; 23:2733. [PubMed: 4058926]

5. Morin CM, Gibson D, Wade J. Self-reported sleep and mood disturbance in chronic pain patients. Clin J Pain. 1998; 14:311-4. [PubMed: 9874009]

6. Power JD, Perruccio AV, Badley EM. Pain as a mediator of sleep problems in arthritis and other chronic conditions. Arthritis Care \& Research. 2005; 53:911-919. [PubMed: 16342098]

7. Moffitt PF, Kalucy EC, Kalucy RS, Baum FE, Cooke RD. Sleep difficulties, pain and other correlates. J Intern Med. 1991; 230:245-9. [PubMed: 1895046]

8. Smith MT, Perlis ML, Smith MS, Giles DE, Carmody TP. Sleep quality and presleep arousal in chronic pain. J Behav Med. 2000; 23:1-13. [PubMed: 10749008]

9. Cooperman N, Mullin F, Kleitman N. Studies on the physiology of sleep: XI. Further observations on the effects of prolonged sleeplessness. American Journal of Physiology--Legacy Content. 1934; 107:589-593.

10. Onen SH, Alloui A, Gross A, Eschallier A, Dubray C. The effects of total sleep deprivation, selective sleep interruption and sleep recovery on pain tolerance thresholds in healthy subjects. J Sleep Res. 2001; 10:35-42. [PubMed: 11285053]

11. Kundermann B, Spernal J, Huber MT, Krieg JC, Lautenbacher S. Sleep deprivation affects thermal pain thresholds but not somatosensory thresholds in healthy volunteers. Psychosom Med. 2004; 66:932-7. [PubMed: 15564360]

12. Roehrs T, Hyde M, Blaisdell B, Greenwald M, Roth T. Sleep loss and REM sleep loss are hyperalgesic. Sleep. 2006; 29:145-51. [PubMed: 16494081]

13. Smith MT, Edwards RR, McCann UD, Haythornthwaite JA. The effects of sleep deprivation on pain inhibition and spontaneous pain in women. Sleep. 2007; 30:494-505. [PubMed: 17520794]

14. Rainville P, Feine JS, Bushnell MC, Duncan GH. A psychophysical comparison of sensory and affective responses to four modalities of experimental pain. Somatosens Mot Res. 1992; 9:265-77. [PubMed: 1492527]

15. Moldofsky H, Scarisbrick P. Induction of neurasthenic musculoskeletal pain syndrome by selective sleep stage deprivation. Psychosom Med. 1976; 38:35-44. [PubMed: 176677]

16. al'Absi M, Petersen KL, Wittmers LE. Adrenocortical and hemodynamic predictors of pain perception in men and women. Pain. 2002; 96:197-204. [PubMed: 11932075]

17. Lowery D, Fillingim RB, Wright RA. Sex differences and incentive effects on perceptual and cardiovascular responses to cold pressor pain. Psychosom Med. 2003; 65:284-91. [PubMed: 12651996]

18. Kim H, Neubert JK, Rowan JS, Brahim JS, Iadarola MJ, Dionne RA. Comparison of experimental and acute clinical pain responses in humans as pain phenotypes. J Pain. 2004; 5:377-84. [PubMed: 15501195] 
19. Fillingim RB, King CD, Ribeiro-Dasilva MC, Rahim-Williams B, Riley JL 3rd. Sex, gender, and pain: a review of recent clinical and experimental findings. J Pain. 2009; 10:447-85. [PubMed: 19411059]

20. Unruh AM. Gender variations in clinical pain experience. Pain. 1996; 65:123-67. [PubMed: 8826503]

21. Carter JR, Durocher JJ, Larson RA, DellaValla JP, Yang H. Sympathetic neural responses to 24hour sleep deprivation in humans: sex differences. Am J Physiol Heart Circ Physiol. 2012; 302:H1991-7. [PubMed: 22408018]

22. Yang H, Durocher JJ, Larson RA, Dellavalla JP, Carter JR. Total sleep deprivation alters cardiovascular reactivity to acute stressors in humans. J Appl Physiol. 2012; 113:903-8. [PubMed: 22815387]

23. Azevedo E, Manzano GM, Silva A, Martins R, Andersen ML, Tufik S. The effects of total and REM sleep deprivation on laser-evoked potential threshold and pain perception. Pain. 2011; 152:2052-8. [PubMed: 21624774]

24. Lentz MJ, Landis CA, Rothermel J, Shaver JL. Effects of selective slow wave sleep disruption on musculoskeletal pain and fatigue in middle aged women. J Rheumatol. 1999; 26:1586-92. [PubMed: 10405949]

25. Moldofsky H, Scarisbrick P, England R, Smythe H. Musculosketal symptoms and non-REM sleep disturbance in patients with "fibrositis syndrome" and healthy subjects. Psychosom Med. 1975; 37:341-51. [PubMed: 169541]

26. Affleck G, Urrows S, Tennen H, Higgins P, Abeles M. Sequential daily relations of sleep, pain intensity, and attention to pain among women with fibromyalgia. Pain. 1996; 68:363-8. [PubMed: 9121825]

27. Harding SM. Sleep in fibromyalgia patients: subjective and objective findings. Am J Med Sci. 1998; 315:367-76. [PubMed: 9638893]

28. Marin R, Cyhan T, Miklos W. Sleep disturbance in patients with chronic low back pain. Am J Phys Med Rehabil. 2006; 85:430-5. [PubMed: 16628150]

29. Marty M, Rozenberg S, Duplan B, Thomas P, Duquesnoy B, Allaert F. Quality of sleep in patients with chronic low back pain: a case-control study. Eur Spine J. 2008; 17:839-44. [PubMed: 18389288]

30. Artner J, Cakir B, Spiekermann JA, Kurz S, Leucht F, Reichel H, Lattig F. Prevalence of sleep deprivation in patients with chronic neck and back pain: a retrospective evaluation of 1016 patients. J Pain Res. 2013; 6:1-6. [PubMed: 23300350]

31. Stone AA, Broderick JE, Porter LS, Kaell AT. The experience of rheumatoid arthritis pain and fatigue: examining momentary reports and correlates over one week. Arthritis Care Res. 1997; 10:185-93. [PubMed: 9335630]

32. Drewes AM, Nielsen KD, Hansen B, Taagholt SJ, Bjerregard K, Svendsen L. A longitudinal study of clinical symptoms and sleep parameters in rheumatoid arthritis. Rheumatology (Oxford). 2000; 39:1287-9. [PubMed: 11085813]

33. Lavigne G, Zucconi M, Castronovo C, Manzini C, Marchettini P, Smirne S. Sleep arousal response to experimental thermal stimulation during sleep in human subjects free of pain and sleep problems. Pain. 2000; 84:283-90. [PubMed: 10666533]

34. Drewes AM, Nielsen KD, Arendt-Nielsen L, Birket-Smith L, Hansen LM. The effect of cutaneous and deep pain on the electroencephalogram during sleep--an experimental study. Sleep. 1997; 20:632-40. [PubMed: 9351131]

35. Lavigne GJ, Zucconi M, Castronovo V, Manzini C, Veglia F, Smirne S, Ferini- Strambi L. Heart rate changes during sleep in response to experimental thermal (nociceptive) stimulations in healthy subjects. Clin Neurophysiol. 2001; 112:532-5. [PubMed: 11222976]

36. Roehrs TA, Harris E, Randall S, Roth T. Pain sensitivity and recovery from mild chronic sleep loss. Sleep. 2012; 35:1667-72. [PubMed: 23204609]

37. Fadda P, Tortorella A, Fratta W. Sleep deprivation decreases mu and delta opioid receptor binding in the rat limbic system. Neurosci Lett. 1991; 129:315-7. [PubMed: 1660582] 
38. Ukponmwan OE, Rupreht J, Dzoljic MR. REM sleep deprivation decreases the antinociceptive property of enkephalinase-inhibition, morphine and cold-water-swim. Gen Pharmacol. 1984; 15:255-8. [PubMed: 6376276]

39. Haack M, Lee E, Cohen DA, Mullington JM. Activation of the prostaglandin system in response to sleep loss in healthy humans: potential mediator of increased spontaneous pain. Pain. 2009; 145:136-41. [PubMed: 19560866]

40. Fillingim RB, Maixner W. The influence of resting blood pressure and gender on pain responses. Psychosom Med. 1996; 58:326-32. [PubMed: 8827795]

41. Myers CD, Robinson ME, Riley JL 3rd, Sheffield D. Sex, gender, and blood pressure: contributions to experimental pain report. Psychosom Med. 2001; 63:545-50. [PubMed: 11485107]

42. Keogh E, Bond FW, Hanmer R, Tilston J. Comparing acceptance- and control- based coping instructions on the cold-pressor pain experiences of healthy men and women. Eur J Pain. 2005; 9:591-8. [PubMed: 16139188]

43. Edwards RR, Haythornthwaite JA, Sullivan MJ, Fillingim RB. Catastrophizing as a mediator of sex differences in pain: differential effects for daily pain versus laboratory-induced pain. Pain. 2004; 111:335-41. [PubMed: 15363877]

44. Sarlani E, Farooq N, Greenspan JD. Gender and laterality differences in thermosensation throughout the perceptible range. Pain. 2003; 106:9-18. [PubMed: 14581105]

45. Nielsen CS, Stubhaug A, Price DD, Vassend O, Czajkowski N, Harris JR. Individual differences in pain sensitivity: genetic and environmental contributions. Pain. 2008; 136:21-9. [PubMed: 17692462]

46. Keogh E, Hatton K, Ellery D. Avoidance versus focused attention and the perception of pain: differential effects for men and women. Pain. 2000; 85:225-230. [PubMed: 10692622]

47. Jones A, Zachariae R, Arendt-Nielsen L. Dispositional anxiety and the experience of pain: genderspecific effects. Eur J Pain. 2003; 7:387-95. [PubMed: 12935790]

48. Pud D, Yarnitsky D, Sprecher E, Rogowski Z, Adler R, Eisenberg E. Can personality traits and gender predict the response to morphine? An experimental cold pain study. Eur J Pain. 2006; 10:103-112. [PubMed: 16310713]

49. Tousignant-Laflamme Y, Rainville P, Marchand S. Establishing a link between heart rate and pain in healthy subjects: a gender effect. J Pain. 2005; 6:341-7. [PubMed: 15943955]

50. Stening K, Eriksson O, Wahren L, Berg G, Hammar M, Blomqvist A. Pain sensations to the cold pressor test in normally menstruating women: comparison with men and relation to menstrual phase and serum sex steroid levels. Am J Physiol Regul Integr Comp Physiol. 2007; 293:R1711-6. [PubMed: 17652363]

51. Fillingim RB, Maixner W, Girdler SS, Light KC, Harris MB, Sheps DS, Mason GA. Ischemic but not thermal pain sensitivity varies across the menstrual cycle. Psychosom Med. 1997; 59:512-20. [PubMed: 9316184] 


\section{Highlights}

- 24-hour sleep deprivation augments perceived pain to cold pressor test

- $\quad$ Our findings are consistent for both mean and peak pain responses

- $\quad$ Gender does not appear to significantly impact our findings 


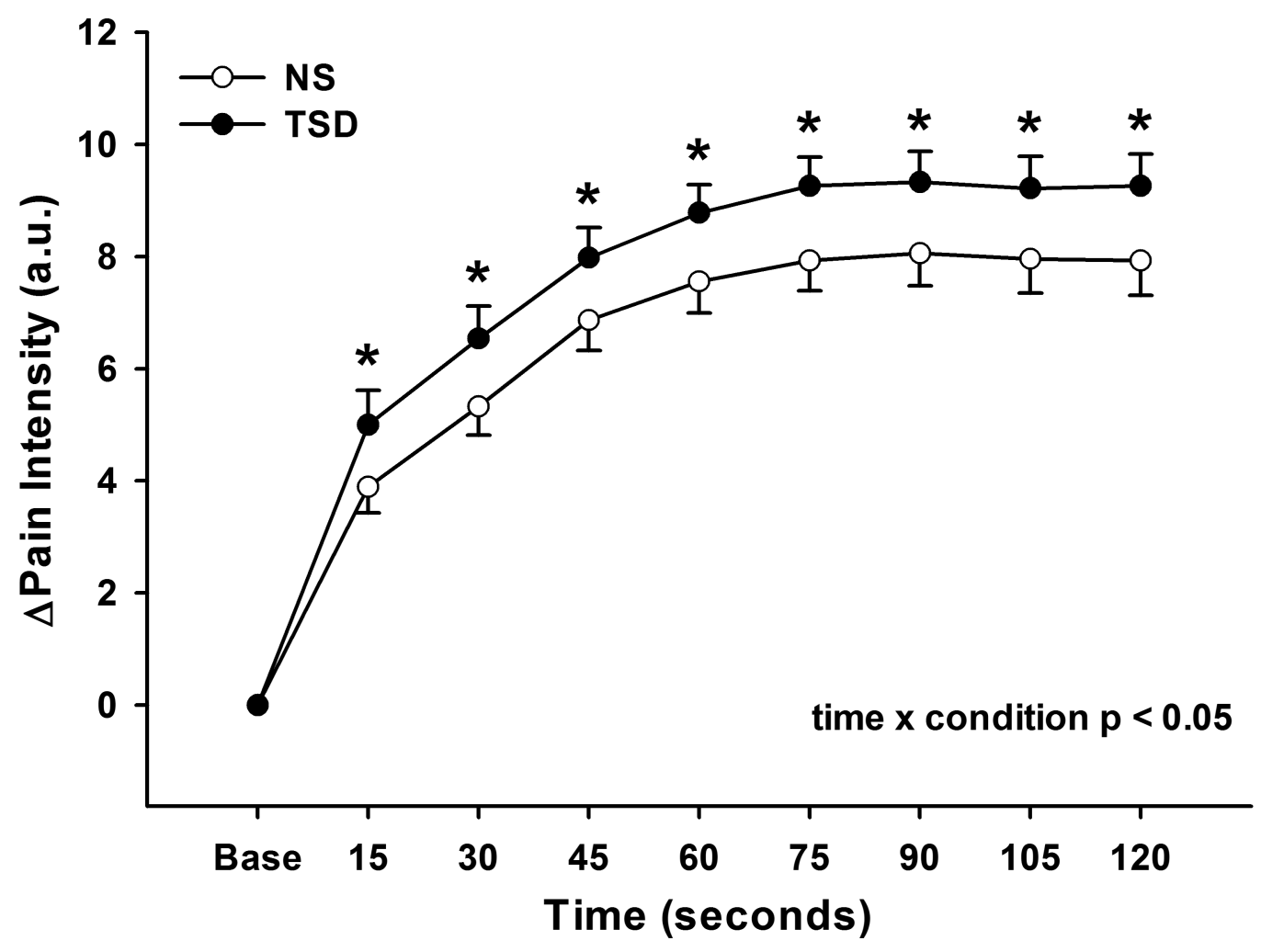

Figure 1.

Changes in perceived pain intensity during 2-minute cold pressor test following normal sleep (NS) and 24-hour total sleep deprivation (TSD) in 27 healthy subjects (14 men, 13 women). TSD augmented the perceived pain response to CPT. * ${ }^{*}<0.05$; NS vs TSD. 

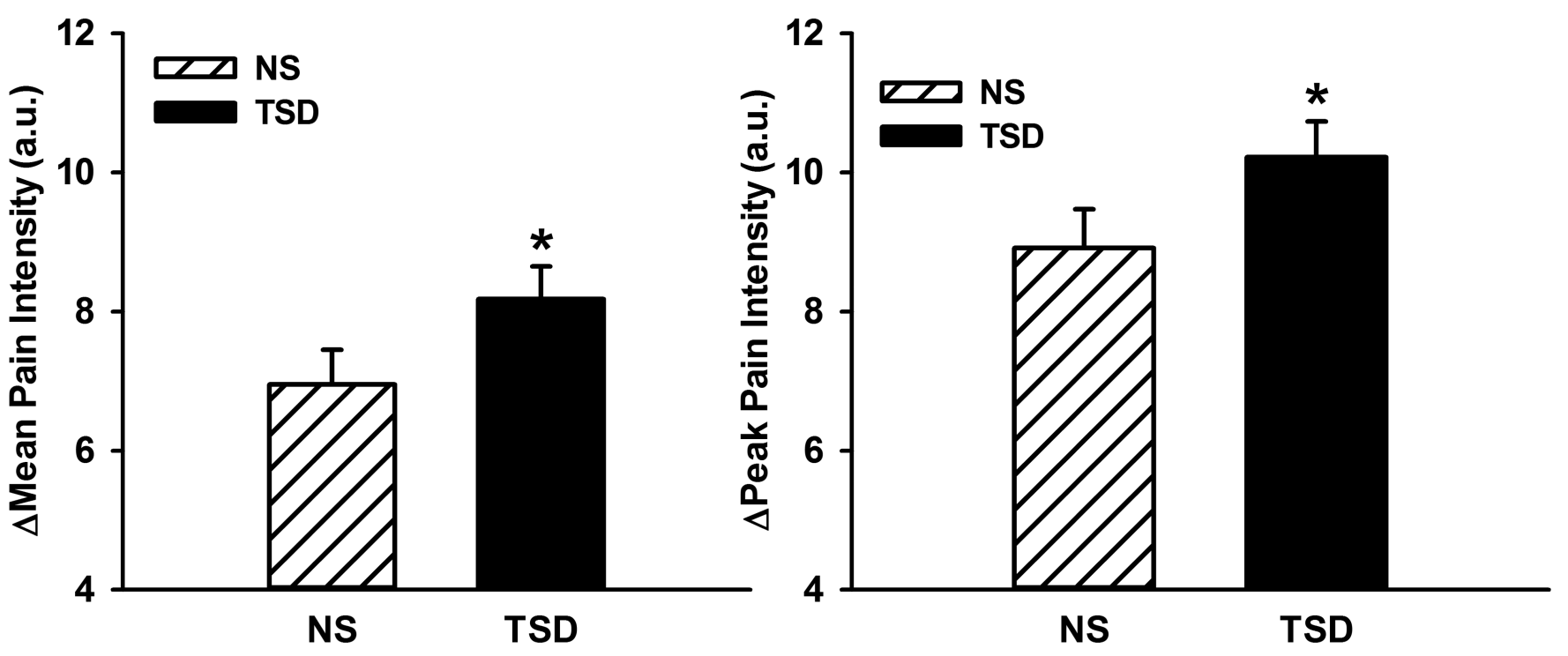

Figure 2.

Changes in mean and peak pain intensity during 2-minute cold pressor test (CPT) following normal sleep (NS) and 24-hour total sleep deprivation (TSD) in 27 healthy subjects(14 men, 13 women). TSD elevated the mean and peak perceived pain response to CPT. * $p<0.05$, NS vs TSD. 


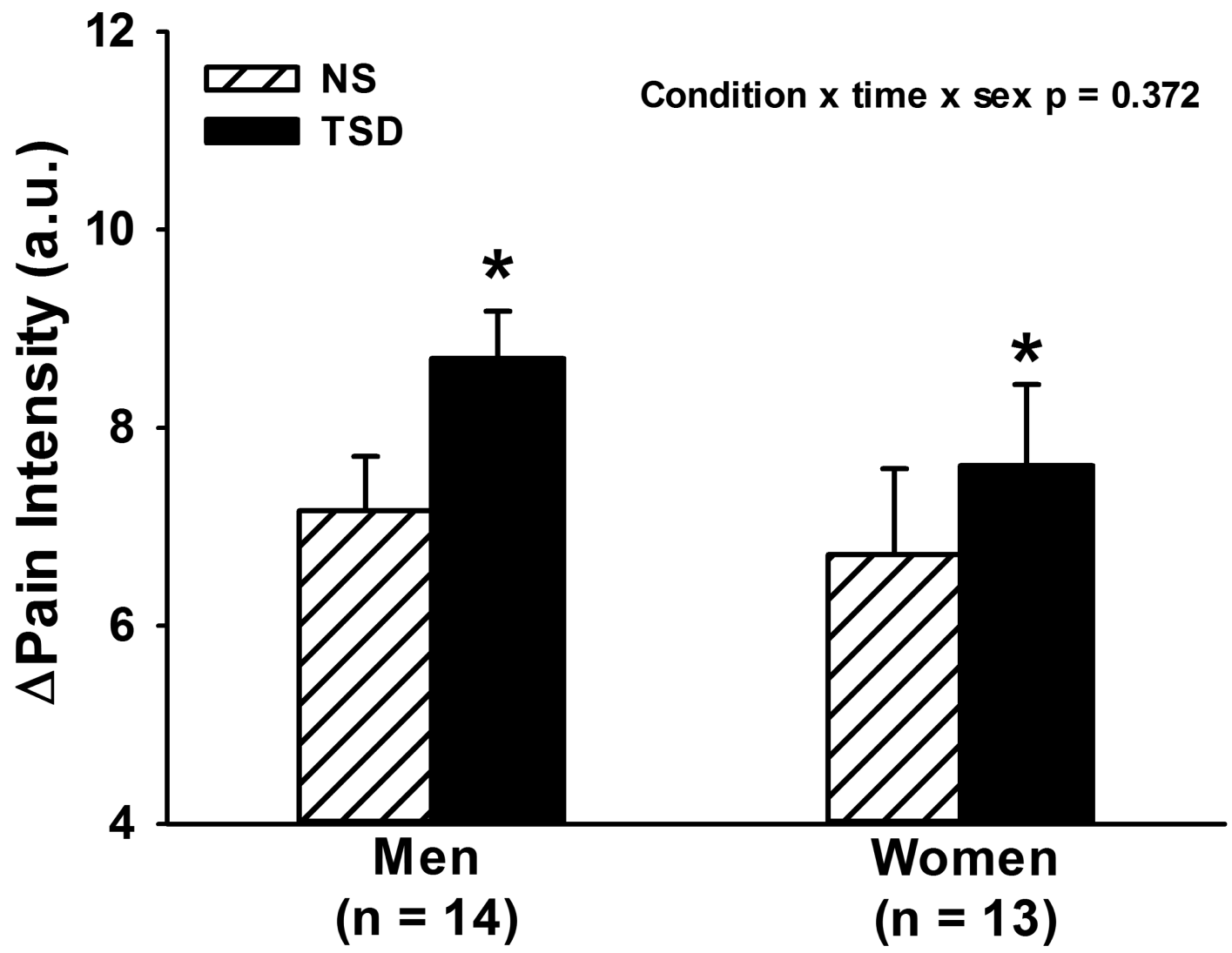

Figure 3.

Mean changes in pain intensity during 2-minute cold pressor test (CPT) in men and women. CPT significantly augmented perceived pain following 24-hour total sleep deprivation (TSD) compared to normal sleep (NS) in both men and women, however, there were no sex differences. ${ }^{*} \mathrm{p}<0.05$, NS vs. TSD. 


\section{Table 1}

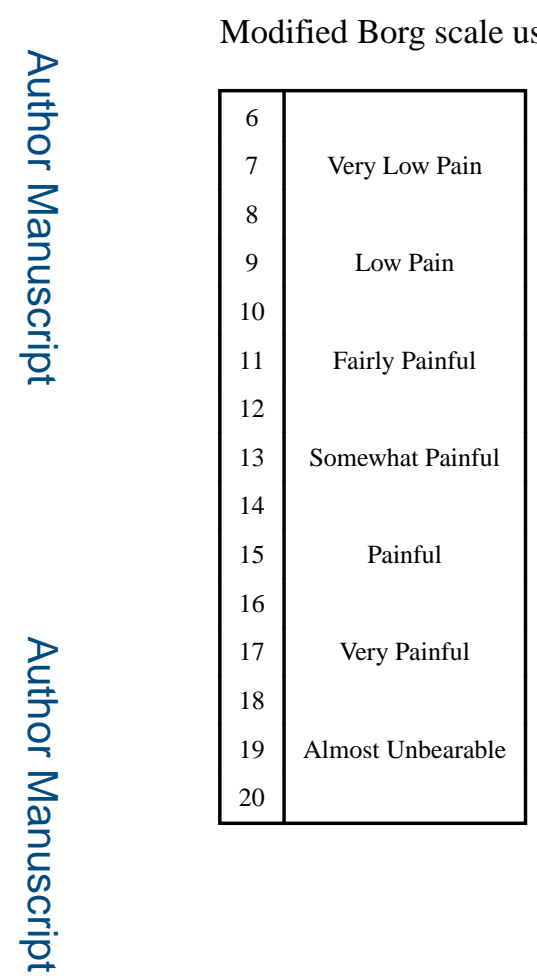

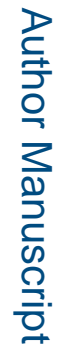

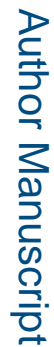

Scand J Pain. Author manuscript; available in PMC 2017 October 01. 


\section{Table 2}

Perceived pain responses to cold pressor test in men and women.

\begin{tabular}{lccccccc} 
& \multicolumn{2}{c}{ Men } & \multicolumn{2}{c}{ Women } & \multicolumn{2}{c}{ P-values } \\
Variable & NS & TSD & NS & TSD & Condition & Sex & Condition $\times$ Sex \\
\hline$\Delta$ Pain Average & $7.2 \pm 0.6$ & $8.7 \pm 0.5$ & $6.7 \pm 0.9$ & $7.6 \pm 0.8$ & 0.001 & 0.205 & 0.186 \\
$\Delta$ Pain Peak & $9.1 \pm 0.6$ & $11.0 \pm 0.4$ & $8.7 \pm 1.0$ & $9.4 \pm 0.9$ & 0.002 & 0.159 & 0.069 \\
\hline
\end{tabular}

